\title{
The Visible Aspect of Things: Towards a Synchronic Reading of Donald Barthelme
}

\section{Surya Bowyer}

\section{(2) OpenEdition \\ Journals}

Electronic version

URL: https://journals.openedition.org/ejas/12867

DOI: $10.4000 /$ ejas. 12867

ISSN: 1991-9336

Publisher

European Association for American Studies

\section{Electronic reference}

Surya Bowyer, "The Visible Aspect of Things: Towards a Synchronic Reading of Donald Barthelme", European journal of American studies [Online], 13-2 | 2018, Online since 13 August 2018, connection on 08 July 2021. URL: http://journals.openedition.org/ejas/12867 ; DOI: https://doi.org/10.4000/ejas. 12867

This text was automatically generated on 8 July 2021.

Creative Commons License 


\title{
The Visible Aspect of Things: Towards a Synchronic Reading of Donald Barthelme ${ }^{1}$
}

\author{
Surya Bowyer
}

\begin{abstract}
Fragments are the only forms I trust. (Barthelme, “See the Moon?"; Sixty 91)
'Fragments are the only form I trust.' This from a writer of arguable genius, whose works reflect the anxiety he himself must feel, in book after book, that his brain is all fragments... (Oates, "Whose" para. 14 of 19)

The fragment 'See the Moon?' deserves note because it is one of the most clearly autobiographical of Barthelme's fragments and because it contains the line 'Fragments are the only form I trust,' which has become a commonplace in nearly all of Barthelme's criticism. (Warde 53)
\end{abstract}

Donald Barthelme's phrase, above, has become a critical shortcut in discussions of his work. Both Oates and Warde read the line as autobiographical, yet both refuse to justify this claim. Warde declares that the story it comes from, "See the Moon?," is "clearly" autobiographical, whilst Oates makes an unhelpful comment about what Barthelme "must feel." Part of the reason the phrase has been picked up repeatedly is its formal neatness. In its original context, the sentence is set off in its own paragraph, leading to the impression that it is important. Metrically, too, it is enticing: an acephalous variation of five iambic feet. It employs the familiarity of iambic pentameter and yet turns it into an almost-a fragment.

2 This reductionist approach to the line annoyed Barthelme. In an interview with Jerome Klinkowitz carried out between 1971 and 1972, Barthelme himself poses a question on which to end:

KLINKOWITZ: In your story 'See the Moon' one of the characters has the line, 'Fragments are the only forms I trust.' This has been quoted as a statement of your aesthetic. Is it?

BARTHELME: No. It's a statement by the character... that particular line has been richly misunderstood so often (most recently by my colleague J. C. Oates in the 
Times) I have thought of making a public recantation. I can see the story in, say,

Women's Wear Daily. (Barthelme, Not-Knowing 205-6) the line's autobiographic value. Warde, on the other hand, has thirteen years to digest Barthelme's revocation, yet still chooses to maintain an autobiographical interpretation of the line. This fact grows all the more frustrating given that Warde, only a few sentences further into his essay, quotes Barthelme's interview answer. Rather than pick it apart, he proceeds to move immediately on to another story.

But Barthelme does not actually issue a "public recantation" of the phrase. The hypothetical is key here: "I have thought" and "I can see the story in, say" (my emphasis). Rather than recant the phrase, Barthelme affirms that it has been "richly misunderstood." The suggestion is that the line has value if one understands it. Barthelme's explicit reference to the Times piece is notable due to Oates's misquotation: "form," as opposed to Barthelme's use of the plural, "forms." Warde maintains this misquote. It is not clear whether this repeated mistake is the result of a chain of misquotation or an intentional rephrasing. fragment is a "part broken off or otherwise detached from the whole" (OED: sense 1, n.). Form, when used in the context of literature, refers to "the arrangement and order of the different parts of the whole" (OED: sense 9, n.). The misquote is less knotty than Barthelme's original phrasing, as it negates the key opposition: a fragment is predicated on its detachment from a whole, whilst the concept of form relies on the presence of an ordered whole. This negation of the quote's complexity allows Oates and Warde to focus instead on word order-the prioritization of the "stern healthy noun" over the "weak" subject (Oates, "Whose" para. 14). Warde phrases it with less flourish: "the subordinate 'I' and the dominant 'Fragments"' (54). Barthelme's decision to begin the sentence with "Fragments" and place the first person "I" into an unstressed syllabic position is striking, yet by focusing on it Oates and Warde bypass a key knot. By figuring the plural "fragments" as combining to create a singular "form," their misquote makes the fragments parts of the whole. In doing so it denies their defining feature-that they are "detached from the whole." The misquote unmakes the "Fragments" into non-fragments. Barthelme's formulation, with both "Fragments" and "forms" in the plural, instead proposes that each fragment is, in itself, a form. These forms are thus predicated on incompleteness. - "trust." Oates, in stating that the line "concludes with the weak 'I'," not only ignores "trust" but actively redacts it. If this final word had been merely a truism, this lack of attention may have been understandable. But it is not, and deserves further consideration.

7 What would it mean to "trust" forms? Turning back to the OED, trust is defined as "To have faith or confidence in a person, quality, or thing; to rely on." (sense 1, v.) Given that the forms Barthelme speaks of are fragments, and as discussions of form refer to the "visible aspect of a thing" (OED: sense $1 \mathrm{a}, \mathrm{n}$.), to trust forms may be provisionally unpacked as: to rely on the visible aspects of fragments. A key focus of this essay will be to show that Barthelme is an unusually visually-minded writer.

8 A text's visible aspects are not usually the objects of readers' focus. Ferdinand de Saussure's conception of the diachronic and the synchronic, originally applied within 
the context of linguistics, provides a useful framework with which to approach different methods of reading. Saussure uses two perpendicular axes, the axis of simultaneity ( $\mathrm{AB}$ ) and the axis of succession (CD). The diachronic study of language operates on the $C D$ axis, and the synchronic operates on the $A B$ axis (80-83). Conventional reading methods generally approach texts as creating a narrative, with events and utterances occurring within a lattice of causal logic. Succession is the chief principle used to analyze a text, and thus these forms of reading may be termed diachronic. Conversely, methods that do not focus on the lattice of causal logic but instead examine "relations from which the passage of time is entirely excluded" (to borrow from Saussure; 80) may be termed synchronic. Focusing on a text's visible aspects falls into this latter category. This focus is key: not only to the above quote from "See the Moon?," but to Barthelme's work more widely.

Throughout his career, Barthelme sets diachronic forms of reading against synchronic forms of reading, and in doing so places an emphasis on the visual which has not yet been explored satisfactorily. By exploring how Barthelme uses dashes and lists, I will show that he deploys them as entities which make readers consider texts visually. Then on a more granular level, I will show that Barthelme approaches the hyphen within compound words as a textual interstice that forms a site of non-diachronic interplay. I will contend that this recurrent focus on synchronic forms of reading raises implications regarding causality, disorder, and the place of written texts within contemporary culture.

\section{Mapping a lacuna}

10 Critical responses to Barthelme have largely simplified him into little more than a literary rebel. Alfred Kazin, in his 1974 overview of twentieth-century American fiction, reduces Barthelme to an "antinovelist" who "operates by countermeasures only" (273). Paul Maltby enacts a similarly reductionist approach by placing Barthelme among a host of "dissident" writers. Joyce Carol Oates includes Barthelme in her survey The oxford Book of American Short Stories, whilst leaving out Maltby's other dissidents. Yet Oates's view of Barthelme is not dissimilar to Maltby's and Kazin's. She chooses, by her own admission, an "atypical" Barthelme story for the collection: "The School." To justify this bizarre decision, she asserts her editorial emphasis is on "storytelling" and not "literary experimentation." In doing so, she discounts Barthelme's typical work as being dissident and antinovelist (insofar as novels predicate themselves on storytelling). Oates openly acknowledges that Barthelme is the only "meta-fictionalist" she includes in the collection (556). This acknowledgement places Barthelme into the dissident group, and suggests he only makes it into the Oxford Book due to the existence of "The School." The predominant view of Barthelme within the context of American fiction is that he operates in a nihilistic manner-that he is experimental merely for its own sake.

11 This fashioning of Barthelme into a nihilist underpins Jerome Klinkowitz's Donald Barthelme: An Exhibition. The book remains perhaps the most far-reaching work on Barthelme, yet lacks a central thesis beyond trying to prove The Dead Father is Barthelme's masterpiece. Klinkowitz justifies this lack by asserting Barthelme "knows that probing for something behind a sign is a waste of time" (17). Larry McCaffery, another critic who has written extensively on Barthelme, similarly argues that he 
develops "metafictional strategies" to express the "overwhelming sense that "la vie quotidienne' is not nearly as satisfying as we had hoped" ("Metafictional" 75, 78, 82). Klinkowitz and McCaffery thus place Barthelme into the same reductionist category as Oates, whilst also stressing the nihilistic motivations behind his work.

A nihilistic disappointment in the world also underpins much analysis of Barthelme's use of fragments. McCaffery himself suggests: "we can say that the ambiguous, fragmented, discontinuous structure of his fiction mirrors a condition which exists in society at large, and within many of its individual members" ("Meaning" 70). McCaffery argues that Barthelme's first novel, Snow White (1967), extends this mirroring further, by integrating society into its construction. He argues the novel is "created out of the trashy, too-familiar words we have around us every day" ("Trash" 31). Criticism exploring fragmentation and collage generally focuses on Snow White as the preeminent example within Barthelme's oeuvre, with Zuzanna Ładyga recently proposing a shift away from reading the novel's fragmentary style as a direct reflection of society and towards an understanding of it as corresponding to Emmanuel Levinas's concept of the there is. Rachele Dini proposes a shift in a different direction; by transmuting the analogy of fragments as verbal waste, she proposes a literal reading of waste in Snow White.

Due to this fixation on showing how Barthelme's fragments mirror the wider world, there has been little investigation into the way Barthelme's fragments operate on a granular level. Nicholas Sloboda, in reading Snow White in terms of both Mikhail Bakhtin's concept of heteroglossia and W. J. T. Mitchell's notion of the visual text, would appear to come close. Yet he directs his essay towards positing fragments as a reflection of the world: "Barthelme devises a "mirror" that reflects his at once distinctly playful and postmodern view of the subject, the word, and world" (121). Thus there is a distinct lacuna in Barthelme criticism-one this essay seeks to address. The lacuna is comprised of two dimensions. First, there is a scarcity of analysis of fragments in works apart from Snow White. Second, almost no attention has been paid to the formal intricacies of Barthelme's fragments, nor to why their visible aspects might be significant.

\section{Disruptive dashes}

In his 1987 essay "Not-Knowing," Barthelme expresses a distaste for a particular punctuation mark: "Let me be plain: the semicolon is ugly, ugly as a tick on a dog's belly. I pinch them out of my prose" (Not-Knowing 22). Such pinching is clear from the rarity of a semicolon appearance in Barthelme's work. Yet rather than "plain," this justification seems characteristically facetious. Given a fondness for the dash and ellipsis evident throughout his work, a distaste for semicolons signals a distaste for the explicit linking of clauses. Barthelme prefers to leave the act of linking separate units of meaning to the reader. A moment in "The Genius" typifies this preference:

His mind is filled with ideas for a new- But at this moment a policeman approaches him. 'Beg pardon, sir. Aren't you- 'Yes,' the genius says, smiling.... Tyranny of the gifted over the group, while bringing some advances in the short run, inevitably produces a set of conditions which-

The genius smokes thoughtfully. (Barthelme, Forty 10) 
The dashes produce interruption, a concept centrally opposed to the effect of the semicolon. Semicolons place two independent clauses consecutively after one another due to their being linked, whilst the dash clashes the two units into one another in a seemingly arbitrary, and moreover unexpected, manner.

What, then, separates the dash from the ellipsis-...? After all, the ellipsis also places two units together in an unexpected manner, through the first unit being apparently incomplete. In their influential usage guide The King's English, brothers Henry Watson and Francis George Fowler state that "a dash implies some sort of break," and thus affirm its ability to express interruption. Yet they go on to state it can also imply a "change of intention" (269). This is not a helpful statement when considering the interruptive dash. Whilst the dash and ellipsis "were originally equivalent versions of the same mark," the ellipsis, not the interruptive dash, has become tied to intention (Toner 3). It indicates an intended end: the speaker has chosen to trail off.

7 Barthelme evidently viewed the ellipsis in these terms. In a section of his story "Views of My Father Weeping" (1970), the ellipsis indicates points at which the speaker trails off in the hope his father will respond: "Father, please! ... look at me, Father ... who has insulted you? ..." (Sixty 115). It is an intended trailing off. In "The President" (1968), the ellipsis is again used to signify an intended trailing off, this time to intentionally create ambiguity:

When he has finished speaking I can never remember what he has said. There remains only an impression of strangeness, darkness ... [...] One hears only cadences. Newspaper accounts of his speeches always say only that he 'touched on a number of matters in the realm of ...' (Sixty 53)

8 The trailing off of "in the realm of..." is used to illustrate that the President intentionally creates speeches of "only cadences" so he can avoid disclosing actual content-a common ability among politicians. The ellipsis creates the sense of incompleteness without the utterance actually being uncompleted. The dash, conversely, indicates a stopping dead mid-utterance due to an unforeseen interruption. It cuts short an utterance, leaving it uncompleted.

This is not the only way the dash can be used, nor the only way Barthelme uses it. Another sentence in "The Genius" reads: "He takes long walks through the city streets, noting architectural details-particularly old ironwork" (Forty 9-10). Here the dash operates much like a colon. Rather than interrupting, it offsets and emphasizes the dependent clause at the end of the sentence. Lynne Truss argues that the dash has become popular in contemporary writing "because it is hard to use wrongly" (Truss 157). This multivalence creates problems, as outlined by the Fowlers:

we doubt whether a full stop is ever allowed to stand in the middle of a dash parenthesis, as it of course may in a bracket parenthesis. The reason for the distinction is clear. When we have had a left-hand bracket we know for certain that a right-hand one is due, full stops or no full stops; but when we have had a dash, we very seldom know for certain that it is one of a pair; and the appearance of a full stop would be too severe a trial of our faith. (272)

Due to its wide range of uses, the dash has an unpredictable character-its function in a passage may only become clear retrospectively. In her examination of that most prolific of American dash-users, Emily Dickinson, Susan Howe argues that "Dashes drew liberty of interruption inside the structure of each poem," yet must also acknowledge that their presence means "only Mutability certain" (23). The dash is not 
solely an interruptive element; rather, it introduces a disruptive unpredictability to a text. the story's origin-or rather, to understand that we may never have this understanding. Within the final decade of Barthelme's life, two anthologies of his work were published: Sixty Stories (1981) and Forty Stories (1987). Barthelme had some level of influence in the collection process; for instance, we know he signed off the title of the earlier collection. ${ }^{2}$ Yet whilst the two anthologies' titles mirror one another, their layouts diverge. Sixty Stories' contents page lists stories under headings that group them chronologically by the collection in which they first appeared. Works which have not previously been collected, having instead generally appeared in The New Yorker, are grouped at the end, without a heading but clearly separated from the preceding headings. Forty Stories does not do this. Its contents page is devoid of headings-a monolithic block of story titles greets readers. Works from previous collections are interspersed with works that have not been collected before, in a non-chronological order and without any information of where the story was first published or collected. If one were to read Sixty Stories from cover to cover, the overarching narrative would consist of a chronological review of Barthelme's literary career. If one were to do the same with Forty Stories, a similar narrative would not emerge. The two anthologies thus promote two different forms of reading. Sixty Stories promotes a diachronic approach, with stories progressing through Barthelme in a temporally logical manner. Forty Stories, with its achronological approach and lack of contextual information accompanying its stories, promotes a synchronic approach where each story should be focused on for its own qualities, rather than the role it plays in any overarching narrative.

This synchronic approach hides the peculiarity of "RIF." Of the previously uncollected works in Forty Stories, it is the only one not to have appeared in The New Yorker. Its provenance remains unintelligible. Where did it come from? Why was it not published before 1987? Was it rejected from The New Yorker? If it was, how did it find its way into an anthology of Barthelme's work? But perhaps to ask these questions is to miss the point. Given the way Forty Stories presents its stories, trying to assess "RIF" diachronically in relation to Barthelme's career progression seems erroneous. The anthology asks us to assess each story without this contextual information.

Let me tell you something. New people have moved into the apartment below me and their furniture is, shockingly, identical to mine, the camelback sofa in camelcolored tweed is there as are the two wrong-side-of-the-blanket sons of the Wassily chair and the black enamel near-Mackintosh chairs, they have the pink-and-purple dhurries and the brass quasi-Eames torchères as well as the fake Ettore Sottsass faux-marble coffee table with cannonball legs. I'm shocked, in a state of shock- 
-I taught you that. Overstatement. You're shocked. You reel, you fall, you collapse in Rodrigo's arms, complaining of stress. He slowly begins loosening your stays, stay by stay, singing the great Ah, je vois le jour, ah, Dieu, and the second act is over.

-You taught me that, Rhoda. You, my mentor in all things.

-You were apt Hettie very apt. (Forty 40) short story-presents it not as one character talking to another, but as the narrator addressing the reader. A diachronic approach to reading this opening creates expectations that the story is formed of a single speaker addressing the reader. When this first paragraph is interrupted, the logical progression of the story is thrown into flux. Within three words of speaking, this second speaker solidifies the presence of two characters in the story: "I" and "you." Long, rambling clauses are replaced with short, clipped ones-akin to conversational speech. There is a shift, as the misdirection of the opening gives way to a clear dialogue form.

Given this opening, the dashes seem at first a method of obfuscating the characters' names. But this explanation of the dashes is inadequate, as the obfuscation is counteracted almost immediately. By the third paragraph we know one speaker is called Rhoda, and by the fourth we know the other is called Hettie. Given that the dashes continue to be used as speech prefixes after this point, their purpose cannot be merely to obfuscate. What else do they do?

In attempting to answer this question, it is important to note that the first dash speech prefix is not the first dash in the story. There is one immediately before the switch in speakers-one that we take to signify interruption. This syntactic reading of the dash is diachronic, as syntactic analysis is necessarily time-based. Guy Davenport motions towards approaching Barthelme in a different manner: "Sometimes we can locate all the layers, sometimes not: Barthelme clearly wanted us to remain in the interstices: that's where his poetry is" (72). There is a contradiction here. For if we cannot locate all the layers within Barthelme's work, positioning ourselves in between them-in the "interstices"-would be an impossible task. The negative space of the interstices can only become completely defined once all the layers have been located. Nonetheless, if we overlook this contradiction, as well as the unhelpfully vague term "poetry," Davenport's basic suggestion is intriguing: that the interstices of Barthelme's work are worthy of exploration. If we take the dialogue form to be predicated on a back and forth of segments-ABABAB etc. - the two consecutive dashes that fall on either side of the first paragraph break in "RIF" visually demarcate the border between the first $A$ and $B$ sections of the story. They form visible interstices. Beginning each new section also with a dash visually inscribes borders between each of the utterances on the page itself. Reading the dash thus, not as a feature of syntax but primarily a visual feature of the text, is a synchronic form of reading in that it is not time-based. This synchronic approach drives the focus of reading away from the story's temporal progression and towards the story's visual properties: composition takes precedence over narrative. Whilst the dash exists within the temporality of the story (i.e. in the time between utterances), its meaning is not derived from a time-based analysis of it. Rather, its spatial position is crucial in understanding its purpose to demarcate utterances. Its visible aspect is key. 


\section{Vertical organization}

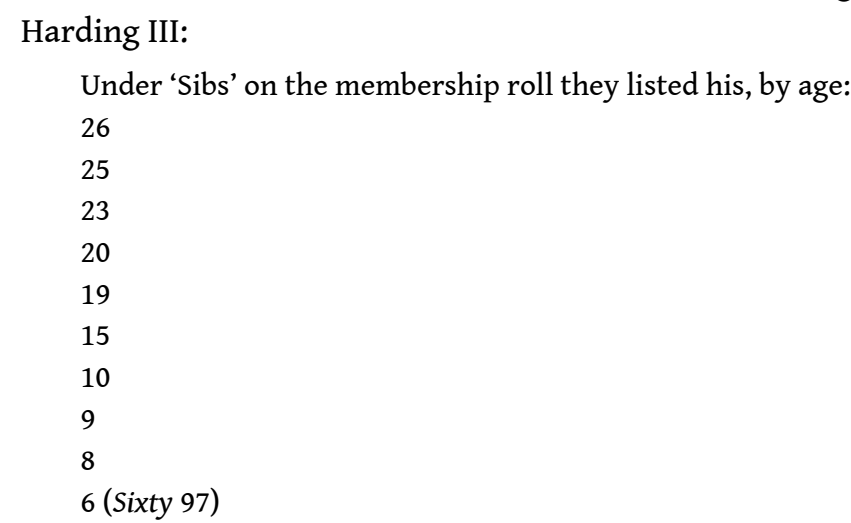
Harding III: "See the Moon?" (1968). In it, we are told of the siblings of a character named Henry

Or are we? We end up learning very little: we cannot even name them. That the list's heading is "Sibs" and not "Sibs' age" suggests the list should provide us not only with their ages but also their names. Each entry in the list is missing key contextualizing material. Maria Konnikova, writing in Barthelme's favourite haunt The New Yorker, affirms that lists are usually used to communicate information in a manner whereby "conceptualization, categorization, and analysis is completed well in advance of actual consumption... And there's little that our brains crave more than effortlessly acquired data" (para. 2 of 7). By forming it out of impenetrable fragments, Barthelme does not create this list to afford the reader "effortlessly acquired data." So why does he create it? It is here useful to return to Konnikova, who argues a list is "inherently captivating" partially due to the fact it "spatially organizes the information" (para. 2 of 7). As the information itself within the "Sibs" list is so slight (and so impenetrable), the list primarily emphasizes the very possibility of spatial organization within a text. By breaking from the left-to-right motion reading conventionally employs, the list calls attention to the possibilities of the visual within written texts.

"The Indian Uprising," another story that originally appeared in Barthelme's 1968 collection Unspeakable Practices, Unnatural Acts, uses a list in an analogous manner:

'The only form of discourse of which I approve,' Miss R. said in her dry, tense voice, 'is the litany. I believe our masters and teachers as well as plain citizens should confine themselves to what can safely be said. Thus when I hear the words pewter, snake, tea, Fad \#6 sherry, serviette, fenestration, crown, blue coming from the mouth of some public official, or some raw youth, I am not disappointed. Vertical organization is also possible,' Miss R. said, 'as in pewter snake tea

Fad \#6 sherry

serviette

fenestration

crown blue.' (Sixty 106)

Presumably the two different presentations of the litany sound the same, even though they are different visually. In some sense, the humor of the passage comes from how 
"[v]ertical organization" is not possible vocally. In making the joke, Barthelme again uses a list to call attention to the possibility of the visual within written texts.

\section{Visible interstices} Barthelme explores visual expression, "Will You Tell Me?" takes the method of presenting utterances used in "RIF" and fashions it, too, into a moment of visual expression:

Dialogue between Paul and Ann:

-You say anything that crawls into your head, Paul, Ann objected.

-Go peddle your hyacinths, Hyacinth Girl.

It is a portrait, Hubert said, composed of all the vices of our generation in the

fullness of their development. (Sixty 38)

The dashes clearly demarcate the voices within this "Dialogue." This moment is the only time the dash is used to inscribe the borders between utterances. Generally, the story shifts abruptly from scene to scene without the use of dashes. ${ }^{3}$ The reference to Ann as the "Hyacinth Girl" is a reference to T. S. Eliot's The Waste Land:

'You gave me the hyacinths first a year ago;

'They called me the hyacinth girl.' (56; 1l. 35-6)

There is a clear semblance in the way The Waste Land and "Will You Tell Me?" approach the presentation of voices: namely, both texts are happy presenting different voices as visually undemarcated from one another. The hyacinth moment in Eliot's poem is one of a number of instances in which an utterance is demarcated, as the two lines are presented within speech marks. Barthelme's allusion thus operates on two levels. First, it aligns "Will You Tell Me?" with The Waste Land, insofar as each text handles polyphony similarly by often refusing to demarcate different voices. Second, it aligns specific moments in both texts where voices are demarcated. The alignment of the two texts' general projects of undemarcation contrasts, and thus emphasizes, this more minute alignment of two moments of demarcation.

In demarcating the beginning of a new utterance, the dash effectively figures the separation of Paul and Ann in the physical inscription of the horizontal line. To occur, dialogues require two defined speakers, and thus this separation is a prerequisite of the form. Yet the demarcation the dash provides is significant not only to the "Dialogue" itself, but is significant also to the way Barthelme enacts the next shift in scene. Chris Power suggests the story has "something of the quality of a film watched in fast forward, the familiar connective tissue of plot and commentary almost entirely jettisoned" (para. 4 of 8), yet does not explore how this lack of "connective tissue" affects the form of the story. The reader knows this next shift has occurred even before the narrative discloses that it is now Hubert who is speaking: the lack of a dash before the utterance signifies that this voice is not within the "Dialogue." The dash thus not only demarcates voices within the "Dialogue," but also demarcates the "Dialogue" from the rest of the narrative which envelopes it. The dash, in forming a visible interstice which signals disruptive shifts in voice and scene, serves as a sort of disconnective tissue. Before the narrative has told us that the scene has shifted, the dash has visually shown us that it has. Synchronic forms of reading are prioritized over diachronic forms. 

voted to try the river in the next town. They have a girl-river there they don't use much" (21). Robert Coover's assessment of Barthelme-"Donald was laconic"-is particularly apt here (Provan para. 3 of 7), for he takes his initial metaphoric image "river of girls" and condenses it into a compound. ${ }^{4}$ In Sloboda's view, "the word 'river' overshadows 'girl', which it is meant to modify" (112). This assessment is syntactic in approach, in that what underlies it is the concept that the latter word should modify the earlier word. Sloboda's issue with the line-that the latter word "overshadows" the former-stems from the fact that the compound resists his diachronic method of reading it. But Barthelme's formulation of how compounds work-"words placed side by side" to create "merged meanings"-is not reliant on time: "a compound noun (such as 'bone-head') or compound adjective, that is, a word placed on top of another word. The first (the one on top) modifies, changes the second. Like a photograph of a photograph" (Not-Knowing 192). Barthelme figures the first word as on top of the second. Sloboda argues the opposite-that the latter word, in his example "river," should modify the first, "girl." In doing so, Sloboda reads the compound diachronically, with the words' temporal progression being fundamental to their interplay. Ładyga, in her Levinasian reading of Barthelme, argues similarly that Barthelme's work suggests that "collage is governed by a specific temporal logic" (2). Barthelme's reversal of temporality in his formulation of "bone" and "head" undermines this diachronic method of reading his work. For if "bone" is on top of "head," as in Barthelme's formulation, the compound is akin to a visual collage piece turned on its side-one encounters the topmost layer before delving into the layers below. The compound must not be approached diachronically.

But there is a problem with approaching compounds as visual collages: the hyphen. Whilst Theodor Adorno argues "inconspicuousness is what punctuation lives by," Truss argues that part of the reason the dash has become so pervasive is due to it being "easy 
to see" compared to other punctuation marks (Adorno 305; Truss 157). This observation, when applied to the shorter but visually comparable hyphen, reveals that in this example of "girl-river" the interstice is not a negative space (unlike in pointillism or collage). The words are not simply "side by side" nor "on top of" one another; rather, the horizontal line of the hyphen visibly figures the site of interplay between the two words. Much like the dashes that demarcate utterances in "RIF" and "Will You Tell Me?', the horizontal line here visually inscribes the borders between units of meaning on the page.

\section{Challenging causality}

Barthelme's recurring focus on synchronic forms of reading raise wider issues regarding causality. For if we are to focus on the visible aspects of his texts over and above the temporal progression of them, the logic of causality which underlies conceptions of narrative is undermined. David Lodge's influential anthology of essays The Art of Fiction uses the opening of "Will You Tell Me?" as the case-study in its section on duration. Lodge rightly notes that within Barthelme's work "causality, continuity, cohesion, consistency in point of view... are also discarded or disrupted" (187). Yet Lodge paradoxically reads Barthelme in terms of one of the things he argues is discarded or disrupted-causality. He argues: "Barthelme implies that people do not act on rational motives, but in response to whim, chance and unconscious drives" (187, my emphasis). The chain of causality, of utterances and actions being in response to previous utterances and actions, is maintained by Lodge. As a result, Lodge overlooks a problematic sentence from the story. The sentence documents the growth of a character named Hilda: "To begin with, she was just a baby, then a four-year-old, then twelve years passed and she was Paul's age, sixteen" (Sixty 37). Lodge's assessment is that "Her growth from infancy to adolescence is summarized in a single sentence of stunning obviousness" (188). Like much of "Will You Tell Me?," the sentence avoids subordination, creating a simplistic tone which feeds into Lodge's dismissal. Yet the sentence handles time curiously, stating that Hilda and Paul's ages match only once twelve years has passed. We would expect Paul and Hilda's ages to roughly correspond throughout their lives-this is how we usually conceptualize the passage of time. The temporal reality of Barthelme's text handles time in a non-continuous, non-linear manner. The lattice of causality-the logic underlining the progression of a text's events-is thrown into flux.

Barthelme's final story, "January" (1987), begins as an interview with fictive journalist turned theologian Thomas Brecker, but progresses into directly engaging with these questions regarding the importance of causality. The general layout of the story is thus. After an introductory paragraph, which contextualizes the location of the interview and Brecker's career and works, the story shifts into a question and answer format: the unnamed Interviewer asks a question, Brecker provides an answer. "January" was first published in The New Yorker, and their online archive entry for it notes that "Towards the end of the interview, the interviewer seems to have disappeared and Brecker is talking without being questioned." This shift occurs when the Interviewer is interrupted mid-question:

INTERVIEWER

On the question of- 


\section{BRECKER}

Remember that I was the opposite of a charismatic figure, not a leader, not even a preacher. (Forty 245)

that each section is compartmentalized-a clear parallel is drawn between his answers to the Interviewer and the monologue-like speech after the Interviewer's disappearance. The monologue segments are presented as answers without questions. Usually, the question-answer form typifies the logic of causal progression which underscores conceptions of narrative: answers come into existence as utterances only because they are prompted by the questions which precede them in the lattice of causal logic. By detaching the later answers in "January" from any preceding questions, Barthelme suggests not only that the relationship between question and answer is not linear or stable, but that a diachronic understanding of utterances-that they are created by and located within a temporal lattice of causal logic-is irrelevant. A given

utterance's cause is never certain. symptoms - a biting in the chest - and wondering, Is this it? (Forty 245) the disappearance later. These two moments locate the two speakers in vastly different ways to accommodate for this. At the moment of interruption, the speakers maintain the dialogic form of the interview: the Interviewer specifically refers to his/her own "question," and the first word of Brecker's response is an imperative directed at the Interviewer. We are thus reminded of the Interviewer's purpose, and also reminded of his/her position as in dialogue with Brecker. In the latter moment, the first where the Interviewer's disappearance becomes apparent, Brecker turns inward: the first word, rather than locate and remind us of the presence of the Interviewer, focuses on Brecker himself. This continues with "my own," the focus on "symptoms" and therefore on Brecker's bodily existence, and the solipsistic "wondering." story refuses to depart from the interview form. The basic principle of speech-prefix followed by segment of speech is maintained in what would otherwise appear to be a monologue. The repeated reminder that it is now only Brecker who is speaking is a comical method of emphasising the disappearance of the Interviewer. For, if we were instead given an unexpectedly long, monolithic section of speech, the Interviewer's disappearance would not be clear-they would look patient, not absent.

compartmentalized sections implies an act of editing has occurred: why do some sentences require a new speech prefix, whilst others do not? As a result, although only Brecker remains speaking, the things he says are figured in dialogue with themselvesakin to the words that form Barthelme's compounds. The clear demarcation of different segments is key, as a singular, monolithic section of speech would preclude this dialogic interplay. 


\section{Reading-watching}

In the 1981 Paris Review interview, J. D. O'Hara addresses the "foreign voices, fragmentation" which this essay has taken as its focus. He asks: "What about the moral responsibility of the artist?... Where in all this evasion of the straightforward does responsibility display itself?" Barthelme responds: "I believe that my every sentence trembles with morality in that each attempts to engage the problematic rather than to present a proposition to which all reasonable men must agree. The engagement might be very small, a word modifying another word" (Not-Knowing 284). Barthelme justifies his interest in the interplay of entities, whether on the "very small level" of compounds ("a word modifying another word") or on a larger level, as a moral attempt to "engage the problematic." But "morality" is a hazy concept, and Barthelme uses O'Hara's question to push the discussion towards a more specific rumination on the place of art:

I think the paraphrasable content in art is rather slight - 'tiny,' as de Kooning puts it. The way things are done is crucial, as the inflection of a voice is crucial. The change of emphasis from the what to the how seems to me to be the major impulse in art since Flaubert, and it's not merely formalism, it's not at all superficial, it's an attempt to reach truth, and a very rigorous one. You don't get, following this path, a moral universe set out in ten propositions, but we already have that. And the attempt is sufficiently skeptical about itself. In this century there's been much stress placed not upon what we know but on knowing that our methods are themselves questionable-our Song of Songs is the Uncertainty Principle. (NotKnowing 284-5)

The most readily paraphrasable content of a short story is its narrative. Barthelme not only thinks of this aspect of a work as "slight," he quotes a visual artist and thus betrays the visual lens with which he views all art, including his own. The "way things are done" takes precedence over the narrative. Insofar as diachronic forms of reading rely on an underlying lattice of causal, temporal progression-a structure of underlying order-Barthelme's rejection of an ordered universe "set out in ten propositions" may be extended to a rejection of diachronic forms of reading. Barthelme is not only aware of the disorder which results from this, but embraces it as part of the modern human condition-that we know "our methods are themselves questionable," and that "Uncertainty" prevails.

Yet for all these theoretical ruminations on the position of the artist in the modern world, there remains a more pragmatic aspect to Barthelme's emphasis on reading synchronically. In 1972 Barthelme won the National Book Award for Children's Literature for the only children's book he ever wrote, The Slightly Irregular Fire Engine. In his acceptance speech, he spoke of his daughter: "I asked my child once what her mother was doing, at a particular moment, and she replied that mother was 'watching a book.' The difficulty is to manage a book worth watching" (Not-Knowing 55). We do not, conventionally, "watch" books. The act of watching something-the television, perhaps -demands a focus on the visible aspects of the thing in a way that conventional (i.e. diachronic) forms of reading do not. Barthelme was writing at a time when written texts were being displaced by visual ones. Prominent American cultural critics such as Neil Postman and E. D. Hirsch both document how the increasing appeal of television in the second half of the twentieth century weakened interest in printed media. Watching usurped reading. Barthelme takes unremarkable forms-dashes, hyphens, lists, speech prefixes-and deploys them in a remarkable manner: rather than their meaning 
primarily stemming from their place within a lattice of causal progression, their purpose is defined by their atemporal, visual aspects. To read Barthelme is to shift the very act of reading away from its diachronic conventions and towards a synchronic approach, for Barthelme creates texts that-much like television-demand to be watched.

\section{BIBLIOGRAPHY}

Adorno, Theodor W. "Punctuation Marks.” Trans. Shierry Weber Nicholsen. Antioch Review 48.3 (Summer 1990): 300-305. Print.

Barthelme, Donald. Forty Stories. Intr. Dave Eggers. London: Penguin, 2005. Print

---. "January." New Yorker. 6 Apr 1987. Online archive entry information accompanying story. Web. 17 Aug 2017.

http://www.newyorker.com/magazine/1987/04/06/january-2

---. Not-Knowing: The Essays and Interviews of Donald Barthelme. Ed. Kim Herzinger. Berkeley, CA: Counterpoint, 1997. Print.

---. Sixty Stories. London: Penguin, 2003. Print.

---. The Slightly Irregular Fire Engine, or The Hithering Thithering Djinn. Woodstock, NY: The Overlook Press, 2006. Print.

---. Snow White. New York, NY: Scribner Paperback Fiction, 1996. Print.

Davenport, Guy. "Style as Protagonist in Donald Barthelme." Review of Contemporary Fiction 11.2. (Summer 1991): 69-74. Print.

de Saussure, Ferdinand. Course in General Linguistics. Trans. Roy Harris. Ed. Charles Bally and Albert Sechehaye. London: Duckworth, 1983. Print.

Dini, Rachele. "The Writing of "Dreck": Consumerism, Waste and Re-use in Donald Barthelme's Snow White." European Journal of American Studies 11.2 (Summer 2016): 1-17. EJAS.revue.com. Web. 17 Aug 2017.

http://doi.org/10.4000/ejas.11588

Eliot, T. S. The Poems of T. S. Eliot. Vol. I, ed. Christopher Ricks and Jim McCue. London: Faber and Faber, 2015. Print.

Fowler, H. W., and F. G. Fowler. The King's English. Oxford: Clarendon Press, 1908. Print.

“form, n.," sense 1a. OED Online. Oxford: Oxford UP. Dec 2016. Web. 17 August 2017.

http://www.oed.com/view/Entry/73421

“form, n.," sense 9. OED Online. Oxford: Oxford UP. Dec 2016. Web. 17 Aug 2017.

http://www.oed.com/view/Entry/73421

“fragment, n.," sense 1. OED Online. Oxford: Oxford UP. Dec 2016. Web. 17 Aug 2017. 
http://www.oed.com/view/Entry/74114

Hirsch, E. D. Cultural Legacy: What Every American Needs to Know. New York, NY: Random House, 1988. Print.

Howe, Susan. My Emily Dickinson. New York: New Directions, 2007. Print.

Kazin, Alfred. Bright Book of Life: American Novelists and Storytellers from Hemingway to Mailer. Notre Dame, IN and London: University of Notre Dame Press, 1974. Print.

Klinkowitz, Jerome. Donald Barthelme: An Exhibition. Durham and London: Duke UP, 1991. Print.

Konnikova, Maria. “A List of Reasons Why Our Brains Love Lists.” New Yorker, 2 Dec 2013. Web. 17 Aug 2017.

http://www.newyorker.com/tech/elements/a-list-of-reasons-why-our-brains-love-lists

Ładyga, Zuzanna. "Fatigue, Indolence and The There Is, Or, The Temporal Logic of Collage in Donald Barthelme's Snow White." European Journal of American Studies 5.3 (Summer 2010): 1-22. Web. 17 Aug 2017.

http://doi.org/10.4000/ejas.8732

Lodge, David. The Art of Fiction. London: Vintage, 2011. Print.

Maltby, Paul. Dissident Postmodernists: Barthelme, Coover, Pynchon. Philadelphia, PA: University of Pennsylvania Press, 1991. Print.

McCaffery, Larry. "Barthelme's Snow White: The Aesthetics of Trash.” Critique 16.3 (January 1975): 19-32. Print.

---. "Donald Barthelme and the Metafictional Muse." SubStance 9.2.27 (1980). Print.

---. “Meaning and Non-Meaning in Barthelme's Fictions." Journal of Aesthetic Education 13.1 (January 1979): 69-79. Print.

Oates, Joyce Carol, ed. The Oxford Book of American Short Stories. Oxford and New York: Oxford UP, 1992. Print.

---. "Whose Side Are You On?-The Guest Word." New York Times Book Review 4 June 1972: 63. Print.

O’Hara, J. D. “Donald Barthelme, The Art of Fiction No. 66.” Paris Review 80 (1981). Web. 17 Aug 2017.

https://www.theparisreview.org/interviews/3228/donald-barthelme-the-art-of-fiction-no-66donald-barthelme

Postman, Neil. Amusing Ourselves to Death: Public Discourse in the Age of Show Business. London and New York, NY: Penguin, 1985. Print.

Power, Chris. "A brief survey of the short story part 16: Donald Barthelme." The Guardian 1 Apr 2009. Web. 17 Aug 2017.

https://www.theguardian.com/books/booksblog/2009/apr/01/donald-barthelme-shortstory\#comments

Provan, Alexander. “Review: Flying to America.” Stop Smiling, 34 (2008). Web. 17 Aug 2017.

http://www.stopsmilingonline.com/story_detail.php?id=988

Sloboda, Nicholas. “Heteroglossia and Collage: Donald Barthelme's Snow White." Mosaic 30.4 (December 1997): 109-213. Print. 
Toner, Anne. Ellipsis in English Literature: Signs of Omission. Cambridge: Cambridge UP, 2015. Print.

Truss, Lynne. Eats, Shoots and Leaves: The Zero Tolerance Approach to Punctuation. New York: Gotham Books, 2004. Print.

“trust, v.," sense 1. OED Online. Oxford: Oxford UP. Dec 2016. Web. 17 Aug 2017.

http://www.oed.com/view/Entry/207006

Warde, William B. “A Collage Approach: Donald Barthelme's Literary Fragments.” Journal of American Culture 8.1 (1985): 51-56. Print.

\section{NOTES}

1. I would like to thank James Cetkovski, whose inimitable guidance was vital to the production of this essay.

2. David Gates attests to this in his introduction to Sixty Stories (Barthelme ix).

3. There is one other dash in the story, coming in the first line of a letter one character writes to another: 'Dear Ann-' (Sixty 42).

4. Coover's comment originally appeared in issue 24 of McSweeney's (2007), in a large section devoted to Barthelme. Several writers contributed opinions on Barthelme; wittily, these three words formed the entirety of Coover's contribution. The issue is out of print.

\section{ABSTRACTS}

This essay seeks to address a distinct lacuna in criticism regarding the American author Donald Barthelme, one comprised of two dimensions. First, there is a scarcity of analysis of fragments in works apart from Snow White. Second, almost no attention has been paid to the formal intricacies of Barthelme's fragments, nor to why their visible aspects might be significant. Arguing that Barthelme is an unusually visually-minded writer, this essay examines the use of fragments in a range of his short stories. A Saussurean framework is used to argue that Barthelme's writing demands we shift the act of reading away from its diachronic conventions and towards a synchronic approach. I analyze such apparently unremarkable textual aspects as dashes, hyphens, and lists, showing that they are used by Barthelme in a way that demands a visual mode of reading. In questioning the significance of causality, this mode of reading has wider implications insofar as it challenges the typical view that the short story should be approached as a form that is driven by narrative.

\section{INDEX}

Keywords: Donald Barthelme, form, visual, visible, synchrony, diachrony, reading, dashes, lists, Ferdinand de Saussure, fragments, interruption, meta-fiction, short story, grammar, punctuation, ellipsis 


\section{AUTHOR}

\section{SURYA BOWYER}

Surya Bowyer received his BA in English Language and Literature from Keble College, Oxford, and is currently studying for an MA in European Culture and Thought at University College London's Center for Multidisciplinary and Intercultural Inquiry. Interrogating vision often forms the point of convergence in his research interests, with recent work on Foucauldian developments in advertising, the form of Chronique d'un été, and the unstable spectator in film. In September he will take up a lecteur post at Paris IV (The Sorbonne). A selection of his shorter form work is available at: http://suryabowyer.com/. 